\title{
Improving of Active Cell Balancing by Equalizing the Cell Energy Instead of the Cell Voltage
}

\author{
Markus Einhorn $^{1}$, Fiorentino Valerio Conte ${ }^{1}$, Juergen Fleig $^{2}$ \\ ${ }^{1}$ Mobility Department, Electric Drive Technologies, AIT Austrian Institute of Technology \\ Giefinggasse 2,1210 Vienna, Austria,E-mail: markus.einhorn@ait.ac.at \\ ${ }^{2}$ Institute of Chemical Technologies and Analytics, Vienna University of Technology \\ Getreidemarkt 9/164ec 1060 Vienna, Austria
}

\begin{abstract}
This article presents how active charge balancing of energy storage devices such as batteries and supercaps can be improved by using the capacity and the state of charge instead of the cell voltage as balancing criterion. Both for charging and discharging an improvement of performance is gained when using the state of charge and the capacity of the cells as information. A battery stack is modeled and a realistic driving cycle is applied to compare the difference between both methods in terms of usable energy. Finally, the simulation is validated by measurements.
\end{abstract}

Keywords: Li-ion battery, active charge balancing, capacity balancing, battery management

\section{Introduction}

Energy storage devices such as batteries and supercaps are usually connected in series to achieve a higher voltage and to provide enough energy e.g. for electric vehicles but also for several other applications. In electrical vehicles, the lithium ion (Li-ion) battery is the most promising energy storage due to its high energy and power density and therefore this article is focused on Li-ion batteries [1,2].

A typical battery stack consists of twelve serially connected single cells which yields a voltage of $50.4 \mathrm{~V}$ when fully charged and $32.4 \mathrm{~V}$ when completely discharged. During the discharging process the open circuit voltage $(O C V)$ of each cell follows the shape of the curve shown in figure 1 .

If several serially connected and fully charged cells with different capacities $C$ become discharged, the cell with the lowest $C$ is the first which reaches the discharging voltage limit $D V L$ (typically $2.7 \mathrm{~V}$ ) as shown in figure 2. Although the cells are not all completely discharged, the discharging process must stop imme- diately to avoid damage on the weakest cell [3]. By shifting the charge from the not completely discharged cells to the discharged cells, the performance of the battery stack can be improved a lot. This process is called active charge balancing as described in literature [4-8].

The current approach is transferring charge from the cell with the largest voltage to the cell with the lowest voltage (voltage balancing) and there are basically two methods. The charge can be transferred using either a capacitor or an inductor as a short-time energy storage. A very promising structure is shown in [10] and [11]. A flyback converter is used to transfer energy either from one cell to the whole stack (top balancing) or from the whole stack to one cell (bottom balancing) as shown in figure 3 .

In Figure 4a the cell voltages of three serially connected cells during one charging and discharging period are shown. The typical charge transfer with voltage balancing is illustrated with arrows. Since only the cell with the lowest voltage and the cell with the highest voltage are essential, a scenario with three serially 


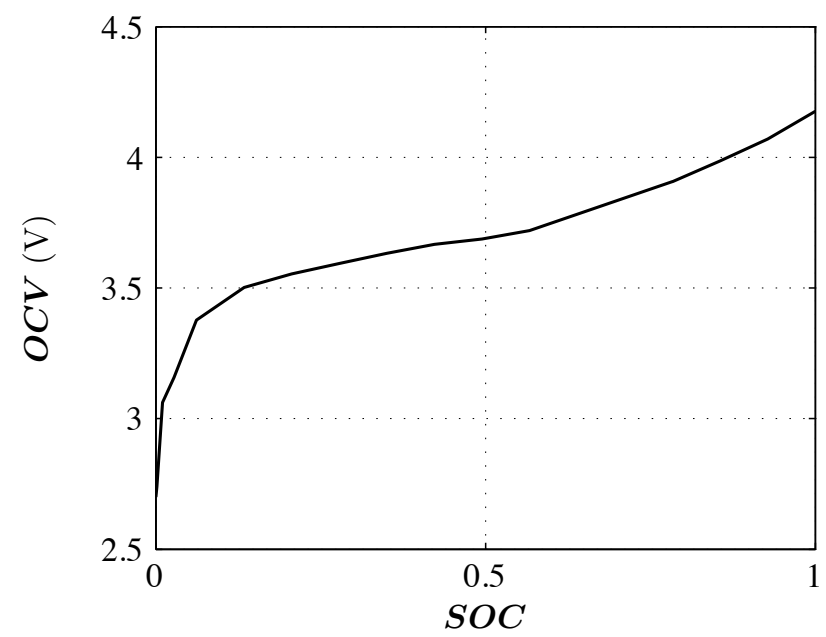

Figure 1: Linear interpolated $O C V$-curve for different state of charge $(S O C)$ gained from tests with the EIG ePLB C020B lithium ion polymer cell [9].

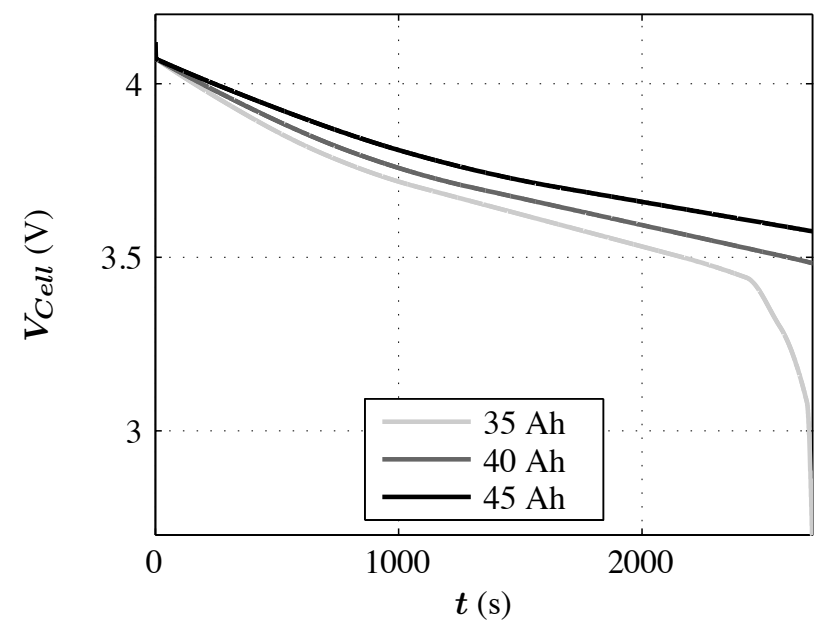

Figure 2: Simulation of the cell voltages of 3 serially connected cells with capacities between $35 \mathrm{Ah}$ and $45 \mathrm{Ah}$ when applying a $40 \mathrm{~A}$ constant discharging current

connected cells is sufficient to analyze the mode of operation. Cell 1 (e.g. $35 \mathrm{Ah}$ ) has the lowest, cell 2 (e.g. $40 \mathrm{Ah}$ ) an intermediate and cell 3 (e.g. $45 \mathrm{Ah}$ ) the highest capacity.

When the charging process starts in phase I, cell 3 has the highest voltage and therefore energy is taken and transferred to cell 1 and cell 2 . Indeed, the energy from cell 3 is transferred to the whole battery stack and since only three cells are present, the energy is split into three equal parts and spread to cell 1 , cell 2 and cell 3 . The net charge transfer though, is from cell 3 to cell 1 and to cell 2 . Cell 1 has the lowest capacity and its cell voltage exceeds the others in phase II. Therefore, energy is now transferred from cell 1 to cell 2 and to cell 3 . When cell

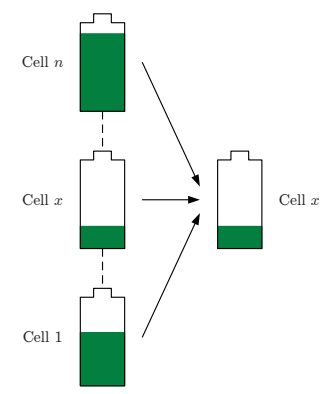

(a)



(b)
Figure 3: Simplified charge transfer in a battery stack with bottom balancing (a) and top balancing (b).

1 reaches $D V L$, the charging process must stop immediately to avoid overcharging of cell 1 though cell 2 and cell 3 are not yet completely charged. With an active balancing system, the charging process could be continued with a severely reduced charging current until all cells are fully charged. This would take much more time and is not considered.

During discharging in phase III, charge is transferred to cell 3 because it has the lowest cell voltage though it has the largest amount of stored energy. In phase IV, cell 1 is supported because of the lowest cell voltage. Both for charging and discharging, cell 1 limits the performance of the battery stack. In phase I and III the wrong cells are balanced because the charge transferred in these two phases must be partially retransferred in phase II and IV. Therefore voltage balancing can be improved.

The drawback of voltage balancing in phase I and III can be eliminated by using the $S O C$ and the actual rated capacity as balancing criterion (capacity balancing) as shown in figure $4 \mathrm{~b}$. While charging, energy from the cell with the lowest energy to full charge (cell 1) is taken. During discharging the cell with the lowest amount of usable energy is supported (cell 1).

In the next section, a specific discharging scenario is simulated and measured to compare the performance of voltage balancing and capacity balancing in terms of usable energy of the battery stack.

\section{Modeling and simulated scenario}

The simulation environment used for the approach is Modelica/Dymola because of the simple and objectoriented possibility to model interdisciplinary relations [12]. The battery model as well as the parameterization procedure is described and validated in [13]. All 


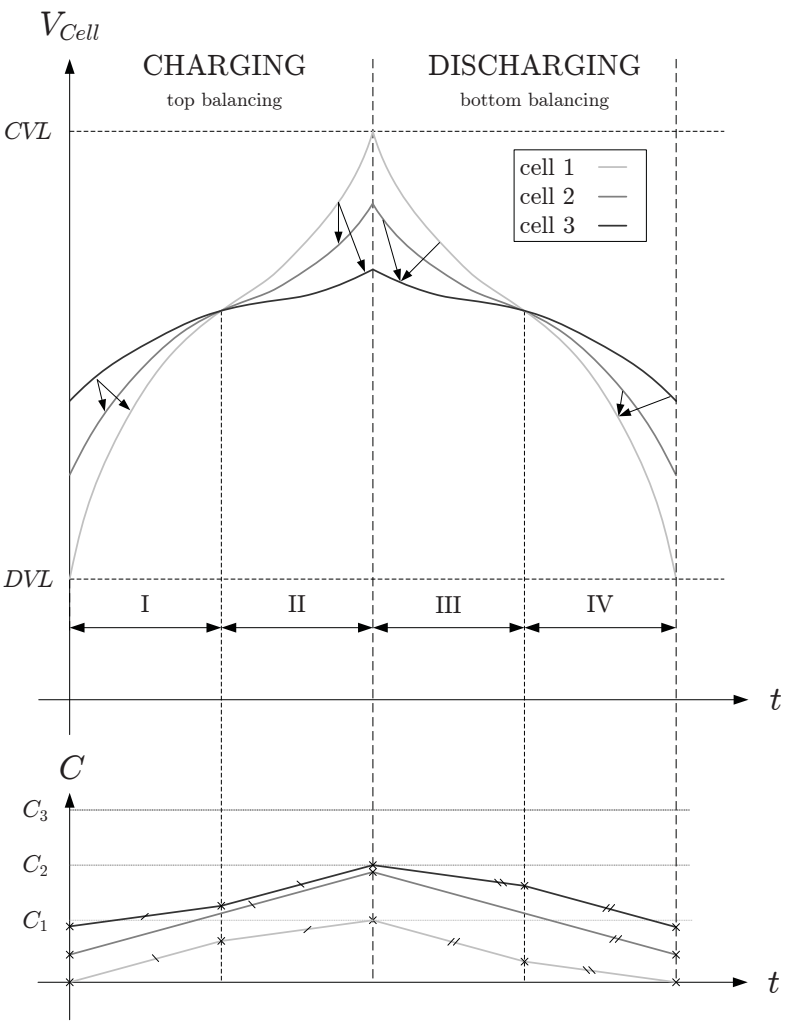

(a)

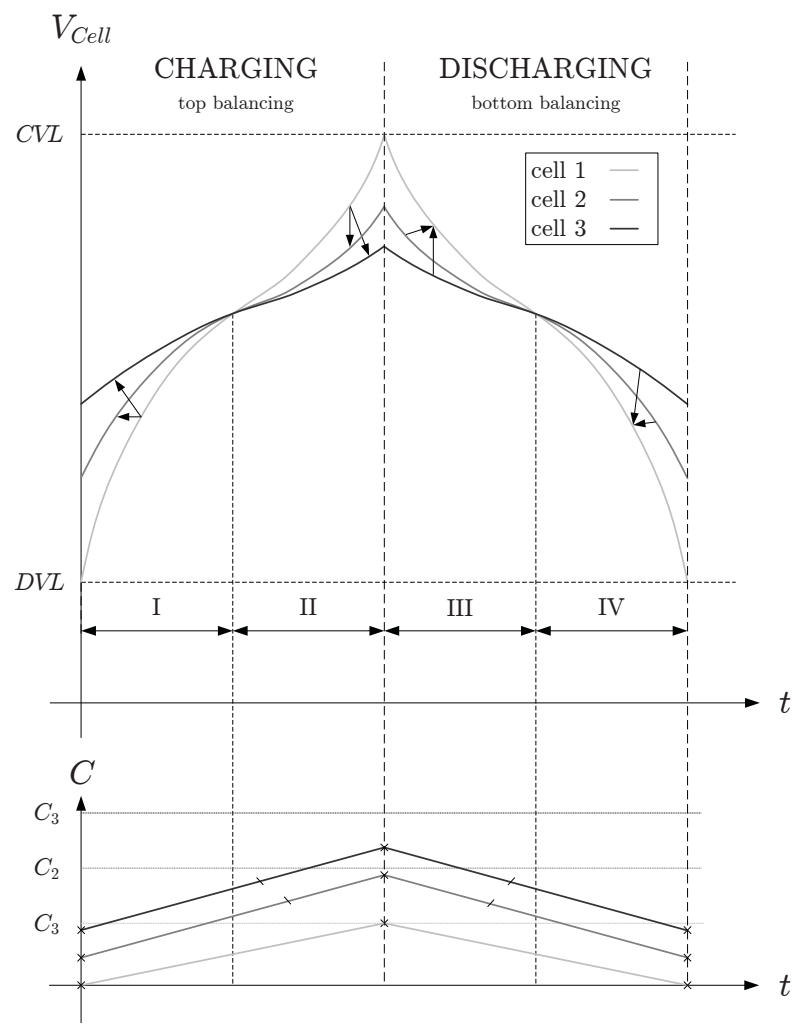

(b)

Figure 4: Balancing with respect to cell voltages (a) and cell capacities (b). The arrows indicate the charge transfer between the cells.

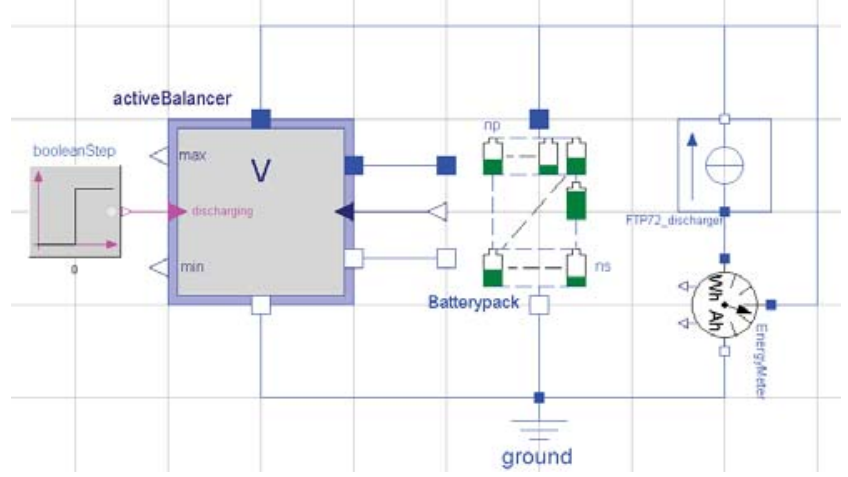

Figure 5: Simulation circuit generated with Modelica/Dymola 6.1.

measurements for the parameterization are performed on the EIG ePLB C020B lithium ion polymer cell [9]. An overview of the model used for the simulation is shown in figure 5 .

Three single cell models of the EIG ePLB C020B lithium ion polymer cell with different capacities and $S O C$ as shown in table 1 are serially connected to a battery stack. This battery stack is getting discharged until one cell reaches $D V L$ (usually the one with the lowest capacity) with a current profile gained from the

\begin{tabular}{cccc}
\hline & $C_{N} / \mathrm{Ah}$ & $C / \mathrm{Ah}$ & $S O C_{i n i}$ \\
\hline cell 1 & 20 & 21.9 & 1 \\
cell 2 & 40 & 41.2 & 0.9 \\
cell 3 & 60 & 65 & 0.8
\end{tabular}

Table 1: Rated cell capacities $C_{N}$, measured capacities $C$ and initial $S O C$ for the simulated scenario.

FTP72 driving cycle as shown in figure 6 [14]. There is an active balancing system connected to the battery stack with a balancing current of $3 \mathrm{~A}$ (single cell side of the dcdc converter) and the energy over the whole discharging process is calculated. The simulation is then validated with the circuit from figure 7. During the whole test the cells are in a climate chamber to minimize temperature effects.

\section{Results and discussion}

The battery stack with the configuration from table 1 has a theoretical stored energy of $406.17 \mathrm{Wh}$. The available discharging energy for different balancing scenarios is shown in figure 8 . Without any balanc- 

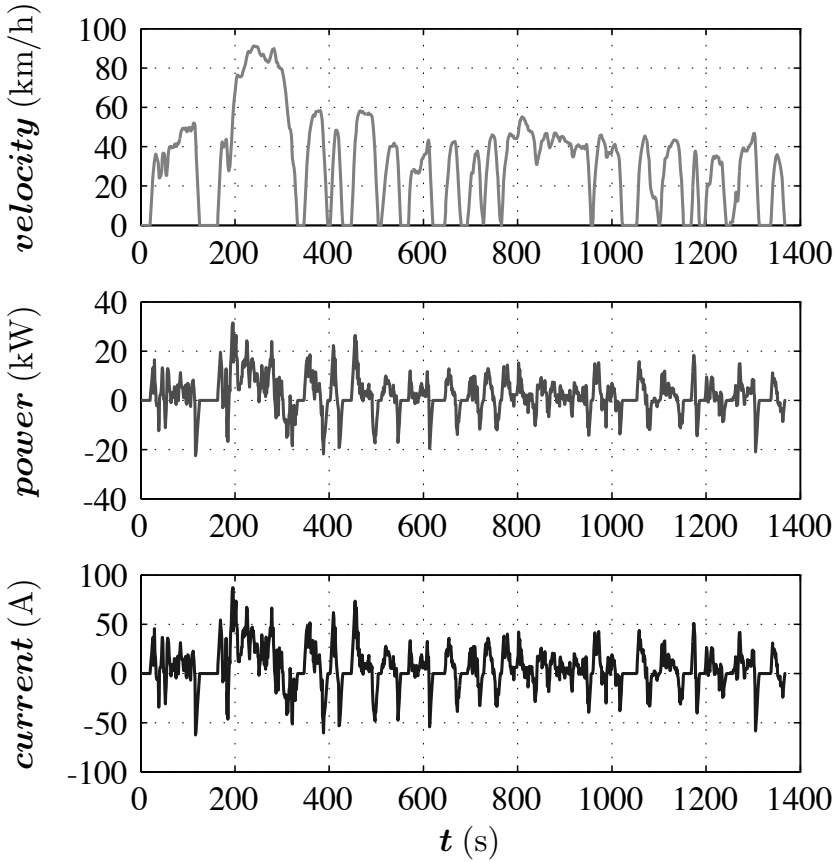

Figure 6: Definition of the FTP72 driving cycle, power consumption of a typical compact electrical vehicle and current requirement from a battery stack with 100 serially connected single cells with a cell voltage of $3.6 \mathrm{~V}$ respectively [14].

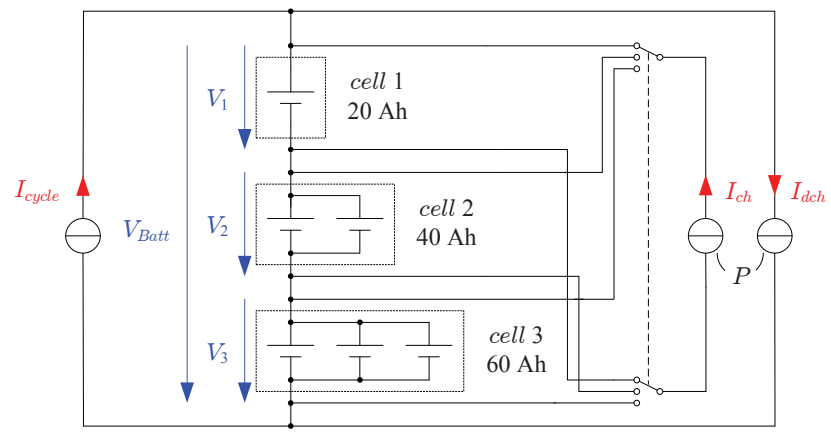

Figure 7: Test circuit to validate the simulation.

ing, the battery stack is as weak as the smallest cell. In this case, the battery stack has a maximum capacity of $21.9 \mathrm{Ah}$ which correlates with an usable energy of $240 \mathrm{Wh}$. Voltage balancing increases the capacity by $27 \%$ to $28.3 \mathrm{Ah}$ or $306 \mathrm{Wh}$. The best performance is accomplished when balancing the capacity. The capacity of the battery stack can be increased by $32 \%$ to $29.1 \mathrm{Ah}$ or $318 \mathrm{Wh}$. Even with capacity balancing, the usable energy is just around $79 \%$ of the theoretical value (406.17 Wh). Therefore the balancing current can be increased.

There is no difference between voltage and capacity balancing during discharging when all cells are fully charged before discharging. In this case the cell with the lowest voltage has also the lowest usable energy

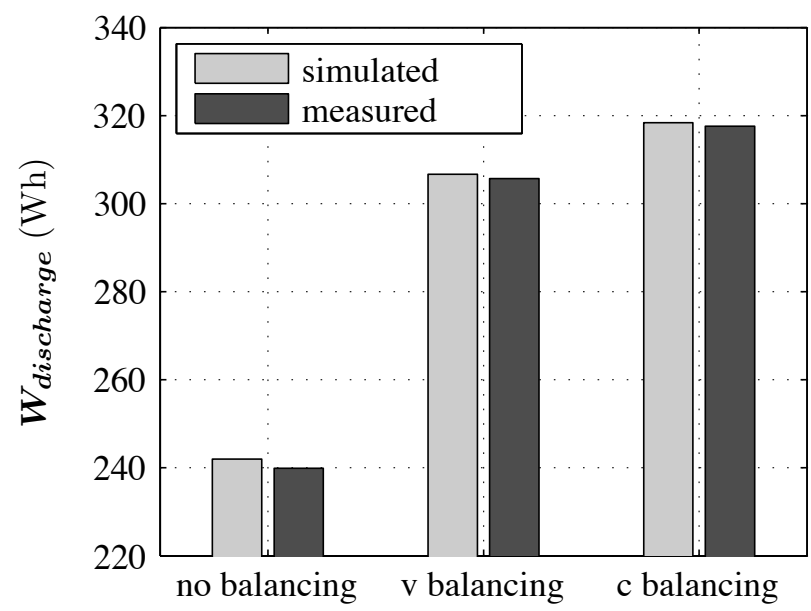

Figure 8: Measured and simulated discharging energy without balancing, with voltage balancing and with capacity balancing.

and therefore the balanced cells are the same. There is also no difference between voltage and capacity balancing during charging if all cells are completely discharged before starting the charging process (the cell with the highest voltage is also the cell with the lowest energy to full charge). When the cells are not all completely charged before discharging, capacity balancing improves the amount of usable energy. When the cells are not all completely discharged before charging, the battery stack can be charged in a shorter time and more energy can be loaded into the battery stack when using capacity balancing.

\section{Conclusion and outlook}

Although active balancing with respect to the cell voltages is already a great advance compared to battery stacks with passive or no balancing systems there is still room left for further improvement. The cell with the lowest voltage (during discharging) in a battery stack is not always the cell which has the lowest amount of energy stored. When having the capacity and the $S O C$ from all cells as balancing criterion the cell which has the least amount of energy stored can be supported. It has been shown that the usable energy of the battery stack can be increased in this case.

One problem could be the exact estimation of the actual capacity of each cell, which varies due to aging and temperature influence. Especially when the battery stack has not been used for a long time the stored values in the battery management system can be inaccurate. Therefore, further work will focus on methods for an accurate estimation of capacity, $S O C$ and the $O C V$ 
vs. $S O C$ curve during battery operation and how inaccuracies in these parameters influence the active capacity balancing.

\section{Acknowledgment}

The authors gratefully acknowledge the support of the Austrian Research Promotion Agency (Oesterreichische Forschungsfoerderungsgesellschaft $\mathrm{mbH}$, FFG) for the research project 8219115 Active Balancing fuer Lithium-Ionen-Batterien in Automobilanwendungen (BALI).

\section{References}

[1] Christian Rosenkranz, Christian Kupfer, and Uwe Koehler. Battery challenges. 21 th International AVL Conference Engine and Environment, September 2009.

[2] Srdjan M. Lukic and Ali Emadi. Charging ahead. IEEE Industrial Electronics Magazine, December 2008.

[3] Andreas Jossen and Wolfgang Weydanz. Moderne Akkumulatoren richtig einsetzen. Reichhardt Verlag, 1 edition, 2006.

[4] Jian Cao, Nigel Schofield, and Ali Emadi. Battery balancing methods: A comprehensive review. IEEE Vehicle Power and Propulsion Conference, September 2008.

[5] Stephen W. Moore and Peter J. Schneider. A review of cell equalization methods for lithium ion and lithium polymer battery systems. Society of Automotive Engineers, January 2001.

[6] Xuezhe Wei and Bing Zhu. The research of vehicle power li-ion battery pack balancing method. IEEE Ninth International Conference on Electronic Measurement and Instruments, August 2009.

[7] Michael Kultgen and Linear Technology. Managing high-voltage lithium-ion batteries in hevs. EDN: Information, News, and Business Strategy for Electronics Design Engineers, April 2009.

[8] Sihua Wen and Texas Instruments. Cell balancing buys extra run time and battery life. Analog Applications Journal, 1Q 2009.

[9] EIG. EIG ePLB CO20B lithium ion polymer cell Datasheet, 2010.

[10] Werner Roessler and Infineon Technologies. Aktiver ladungsausgleich fuer lithium-ionen batterien. ATZelektronik, 3, February 2008.

[11] Werner Roessler and Infineon Technologies. Boost battery performance with active charge-balancing. $E E$ Times-India, July 2008.
[12] Peter Fritzson. Principles of Object-Oriented Modeling and Simulation with Modelica 2.1. IEEE Press, Wiley-Interscience, 2004.

[13] Markus Einhorn, Fiorentino V. Conte, Christian Kral, Juergen Fleig, and Robert Permann. Parametrization of an electrical battery model for dynamic system simulation in electric vehicles. IEEE Vehicle Power and Propulsion Conference, September 2010.

[14] U.S. Environmental Protection Agency. FTP72 Urban Dynamometer Driving Schedule (UDDS).

\section{Authors}



Markus Einhorn was born in Vienna, Austria in 1984 and received the BSc. degree as well as the Dipl.-Ing. degree in electrical engineering and the $\mathrm{PhD}$ degree in technical chemistry all from the Vienna University of Technology in 2008, 2009 and 2011, respectively.

He is currently a Scientist at the Mobility Department, Electric Drive Technologies at the AIT Austrian Institute of Technology in Vienna, Austria. His recent work is focused on design and modeling of power electronics and energy storages with emphasis on battery management systems and aging phenomena of Li-ion battery cells.

Dr. Einhorn is a member of the Institute of Electrical and Electronics Engineers (IEEE), the Austrian Electrotechnical Association (OVE) and the Modelica Association.

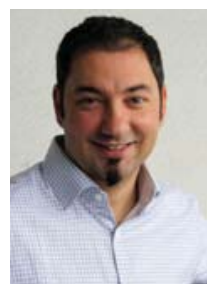

Fiorentino Valerio Conte received his $\mathrm{PhD}$ in transportation at the University of Pisa in 2003. He joined the AIT Austrian Institute of Technology in 2003 after working in a German R\&D department.

Dr. Conte is energy storage group leader within AIT. He leads projects dealing with energy storage systems for HEVs as well as EVs and he has over 10 years of experience in the research of advanced powertrains. Believing in the importance of the dissemination and the networking he is involved within the activities of the International Energy Agency.

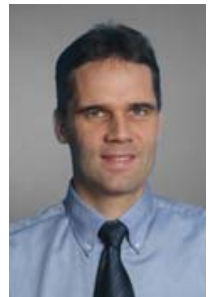

Juergen Fleig received his Diploma degree in Physics in 1991 (University of Tuebingen, Germany) and his $\mathrm{PhD}$ in Chemistry in 1995 (Max-Planck-Institute of Solid State Research, Stuttgart, Germany).

After working as a researcher at the same institute for several further years he accepted a position as professor of electrochemistry at Vienna University of Technology in 2005. His main research subjects are electroceramics and materials for electrochemical energy conversion devices including basic investigations on the physical and chemical processes determining the cell efficiencies. 